\title{
The One Weird Old Trick to Frustrate Online Scammers, Reduce Fees for Consumers, and Make Americans Happier with Their Finances
}

\section{MPP Professional Paper}

In Partial Fulfillment of the Master of Public Policy Degree Requirements

The Hubert H. Humphrey School of Public Affairs

The University of Minnesota

Will Stancil

July $12^{\text {th }}, 2013$

Signature below of Paper Supervisor certifies successful completion of oral presentation and completion of final written version:

Professor Robert Kudrle

Professor Daniel Schwarcz
$7 / 12 / 2013$

Date, oral presentation
$7 / 12 / 2013$

Date, paper completion 
In the late 2000s, an unusual new marketing campaign exploded across the internet. Visitors to a wide range of popular websites-social networks, news outlets, entertainment sites-were subjected to an odd, intriguing banner ad: "Try this one strange trick to reduce belly fat!" The ad's pitch was bizarre and compelling: it was hard not to wonder what the amazing tip was, and millions of people clicked to find out. ${ }^{1}$

These curious consumers were indeed met with a trick, but not the one they'd hoped for. They were first subjected to fake news articles lauding the medicinal benefits of acai berries, resveratrol pills, and other bogus health products, and then asked to try a free sample. ${ }^{2}$ In order to receive the sample, they entered their home address and credit card information. Only later, by examining credit card statements, would they discover the catch: immediate charges to their account, and multiple monthly recurring subscriptions of $\$ 20$ or more, cleverly disguised so as to be overlooked. ${ }^{3}$ Cancelling the subscriptions, they'd soon find, was harder than signing up had been, requiring multiple phone calls to the proprietors of affiliated websites. ${ }^{4}$

Enterprising acai berry merchants weren't the first to trap consumers in monthly fee arrangements with underhanded methods. Indeed, firms of a much better pedigree had recently used similar tactics. During much of the 1990s, America Online was the country's premiere online community, providing e-mail and a carefully curated "walled garden" of net services. But by the mid-2000s, the company had fallen on hard times. Its walled garden withered as the wider web grew. Customers were learning they could access the same services free on the internet. Nonetheless, AOL retained millions of subscribers, each paying a monthly fee for access to the aging web gateway. Many of these were elderly citizens who believed, erroneously, that they could not quit without losing access to their email accounts or e-mail contacts. ${ }^{5}$ Unsubscribing, however, was more difficult than it sounded. Aspiring non-subscribers could expect to spend an hour on the phone with customer service "retention consultants," bombarded with free offers and trial periods and asked to explain their motives. ${ }^{6}$ In one widely-publicized telephone recording, a customer, fed up with an unhelpful retention consultant, resorted to shouting "CANCEL THE ACCOUNT" nonstop, without pause, for five minutes. The "consultant" still refused to

\footnotetext{
${ }^{1}$ Trine Tsouderos, FTC Cracks Down on Bogus Online News Sites that Are Actually Ads, CHICAGo TRIBUNE, Mar. 22, 2012.

${ }^{2}$ Federal Trade Commission, FTC Stops Online Marketing Scheme that Allegedly Scammed Consumers Out of Hundreds of Millions of Dollars Using 'Free' Trial Offers, http://www.ftc.gov/opa/2011/09/jessewillms.shtm.

${ }^{3}$ Amended Complaint at 21, FTC v. Willms, No. 2:11-cv-8028-MJP (W.D. Wa. Sept. 2, 2011).

${ }^{4}$ Id.

${ }^{5}$ Sara Yin, 75\% of AOL Subscribers Don't Need to Pay, Says Report, PCMAG, http://www.pcmag.com/article2/0,2817,2376167,00.asp.

${ }^{6}$ Ben Popken, AOL Retention Manual Revealed, CONSUMERIST, http://consumerist.com/2006/07/18/aol-retentionmanual-revealed/.
} 
cancel the account. ${ }^{7}$ In response to the resulting backlash (and mounting legal trouble), AOL finally streamlined its cancellation policies-estimating it would lose six million subscribers as a result. ${ }^{8}$

The free market is driven by the assumption that the consumer is the master of his or her purchasing decisions - the world's foremost expert on what he or she really wants. Derived from this is the principle that consumers will buy products that improve their lives, and avoid products that cost more than they're worth. The assumption of consumer independence generally holds when consumers are making an informed, active decision to participate in a commercial transaction. But in the modern world, not all commercial transactions arise from a meeting of the minds between buyer and seller. Instead, the exchange of money is sometimes the result of automatic selling: transactions in which, instead of buying a product outright, a consumer provides authorization for future purchases. This permission, once granted and while unrevoked, enables the seller to extract payments from the consumer, regardless of whether the consumer knows, cares, or is utterly oblivious to the process. Automatic selling exists in many forms, but is unquestionably facilitated by modern debit and credit practices, which enable merchants to obtain payment with virtually no participation from consumers whatsoever.

When transactions can be conducted automatically, the assumption that markets benefit consumers begins to break down. Automatic selling means consumers can agree to subject themselves to significant financial liability without ever realizing it. The consequence is a market full of pitfalls for the unwary. Every day, firms use automatic selling and preauthorized electronic payments to force buyers into making purchases they don't really want.

This paper seeks to resolve many of the harms caused when goods and services are sold to consumers automatically. Part I describes automatic selling and preauthorized payment schemes, detailing their diverse forms, their consequences for consumer decisionmaking, and their frequently deleterious effects. Part II gives an overview of preexisting regulations controlling the use of preauthorized payments, and discusses the weaknesses of current regulators, most notably the FTC. Part III proposes a new solution to the problem, which builds on extant regulation and technology to give consumers easy access to information about the authorizations they have given, and tools to revoke payment preauthorization at will. This solution is simple, unobtrusive and almost purely

\footnotetext{
7 Jane Wells, How Hard Can It Be to Cancel an AOL Account?, MSNBC, http://www.nbcnews.com/id/13447232/ns/business-cnbc_tv/t/how-hard-can-it-be-cancel-aolaccount/\#.UYF2_KKOKSo.

${ }^{8}$ Saul Hansell \& Richard Siklos, In a Shift, AOL Mail to Be Free, N.Y. TIMES, Aug. 3, 2006, available at http://www.nytimes.com/2006/08/03/technology/03warner.html?pagewanted=1\&ref=business.
} 
market-based, improving outcomes by increasing consumer information and honoring consumer preferences.

\section{THE PROBLEM OF AUTOMATIC SELLING}

For the sake of consistency and clarity, it is worth taking a moment to nail down the terminology this paper will be using. This is a context in which small distinctions can be important, but in the real world, there is no established definition for the various practices that will be under discussion. As a result, some of the terms used are of this paper's own devising.

"Automatic selling," as used here, means any commercial transaction for which the buyer has provided authorization in advance, but does not provide authorization at the time of an actual exchange. The exchange can be for goods, money, or both. However, in order to qualify as a commercial transaction, an exchange must place some additional liability on the consumer-it must constitute more than the delivery of payments outstanding. In other words, the preapproved delivery a product to a customer's doorstep, which creates a new legal obligation for the customer to pay the merchant, would qualify as automatic selling, but a customer paying for a product on an installment plan would not qualify, because the obligation was preexisting.

Although selling can be automated in many contexts, this paper focuses on retail commercial sales, in which the average buyer is, for all intents and purposes, a perfect layman. The effects of an automated sale might change dramatically if the buyer is a firm or a sophisticated investor, but those are not the circumstances which generally create abusive practices.

Automatic selling is conceptually distinct from the sales technique known as "negative-option billing," though the two practices are related, can sometimes overlap, and often have similar consequences for consumers. Negative-option billing is when a seller structures a sale in such a way that the buyer's silence is interpreted as acquiescence in the transaction ${ }^{9}$; for instance, a seller delivers a consumer a product, and when it is not returned, sends the consumer an invoice. In theory, negative-option billing can occur with or without prior authorization, because consumer silence is interpreted as itself being authorization contemporaneous with the sale.

In the US, however, an unsolicited delivery is considered a gift and cannot result in a payment obligation for the recipient. ${ }^{10}$ As a result, vendors who want to engage in

\footnotetext{
${ }^{9}$ Federal Trade Commission, Negative Options, January 2009, available at http://www.ftc.gov/os/2009/02/P064202negativeoptionreport.pdf.

${ }^{10}$ US Postal Inspection Service, Receipt of Unsolicited Merchandise, https://postalinspectors.uspis.gov/investigations/MailFraud/fraudschemes/othertypes/UnsolicitedFraud.aspx.
} 
negative-option billing must first obtain prior authorization of some sort from a consumer. At this point, the negative-option scheme effectively becomes an automatic selling scheme as well, albeit one in which the customer has the nominal right to return a delivery for a refund.

It is also important to note that while automatic selling is frequently advertised under the guise of a subscription, all subscription services are not necessarily automatic selling. Nonrefundable subscriptions for a limited term are really just ordinary transactions; even if payments are staggered, they are only installment plans. Very often, however, subscriptions either automatically renew, or allow a customer to avoid further periodic payments through cancellation. When consumers can, by taking some additional action, terminate transactions subsequent to the initial authorization, a subscription enters the realm of automatic selling.

Finally, there is "preauthorized payment," which refers to any situation in which a consumer provides a seller with prior authorization to directly obtain payment from a bank account, credit card, or some other source of funds. ${ }^{11}$ If automatic selling refers to the creation of a legal obligation to pay, preauthorized payment refers to one mechanism for the practical exchange of money between buyers and sellers. A merchant who conducts automatic selling, and has obtained payment preauthorization, has essentially closed out the sale in its entirety: the product is delivered, and payment itself occurs automatically, satisfying the customer's liability.

As with negative-option billing, the presence of preauthorized payment does not necessarily imply that automatic selling is occurring. If there is no additional delivery of goods or services conditional on the payment, and they payments are for a limited term, they might simply represent a non-refundable installment plan. In practice, however, most preauthorized payments schemes are either for ongoing services or product deliveries, or of a variable term, and therefore represent automatic selling.

It is important to note that preauthorized payment is almost inextricably bound together with modern banking and credit practices. In a hypothetical world in which consumers carried all their liquid cash in a wallet, a seller would have to approach the consumer each and every time it wanted to collect a payment. In other words, preauthorized payment is a mechanism derived from the current legal and technological structure of our economy, not from heady concepts about liability in commercial transactions.

\section{A. The Economic Mechanics of Automatic Selling and Preauthorized Payment}

\footnotetext{
${ }^{11}$ In some sources, scheduled or recurring payments are simply referred to as "automatic payments." The most significant feature of these arrangements, however, is non-contemporaneous authorization.
} 
The primary mechanism of automatic selling and preauthorized payment is deceptively simple: both techniques simply shift the burden, in time and effort, of conducting an exchange. If we define transaction costs as all the costs incurred during a transaction in addition to a product's advertised price, we can say that automatic selling simply rearranges transaction costs. In a "traditional" sale, transaction costs are incurred alongside a completed exchange, in the process of finding a seller or buyer, disseminating product information, and determining a price. Automatic sales work differently. Although the initial enrollment of a consumer in an automated plan still involves some upfront transactional expense, subsequent sales or exchanges have no transaction cost at all. But instead of disappearing altogether, these transaction costs are shifted backwards to the termination of the relationship. They are incurred in the process of stopping additional sales or payments from occurring.

The potential value of this arrangement is clear. Consumers who are relatively certain that they will want to make a payment or purchase in the future might prefer to avoid the transactional cost of that exchange by automating it. This is particularly true when the transaction cost is compounded some risk that the planned exchange will fail outright (e.g., the customer forgets to pay his electric bill). Automatic selling allows the consumer to avoid the hassle of completing a transaction and the risk of its unintended failure. Although most of what follows is a critique of automatic selling, its benefits should not be ignored or forgotten. In the right situation, automatic selling and preauthorized payment represent powerful, straightforward, and intuitive tools for simplifying and streamlining commerce.

But automatic selling techniques also create opportunity for unscrupulous merchants. Their economic characteristics can be exploited to burden consumers with unsought purchases and invisible payments. Broadly speaking, shifting transaction costs backwards in time warps market decisionmaking in three ways: it tends to reduce consumer information, it tends to obstruct expression of consumer preferences, and it exacerbates ex ante uncertainty about a product's price and utility.

1. Reduction of Consumer Information

Transaction costs often double as information search costs. Although initiating and negotiating a purchase requires an expenditure of time and effort, a consumer receives important information about the product and its cost in the process.

This process of information dissemination can occur in a number of ways. First and foremost, participants in a traditional transaction generally cannot help but be informed that a transaction is occurring. That may seem obvious, but as will be shown below, this is not the case in every type of transaction! Second, because a traditional transaction forces a consumer to weigh the utility of a good against its cost, the transaction encourages 
consumers to attempt to discern the true value and the true cost of the product in question. The consumer is rewarded for discovering negative information about the product, and the producer is rewarded for communicating positive information. Meanwhile, the cost must be relatively clearly communicated for the transaction to occur at all, because money cannot change hands absent the purchaser's volition. Indeed, if the entire payment is made upfront, the consumer cannot help but be fully aware of the cost-the amount has been taken out of his or her wallet, or at the least, appears at the bottom of the receipt .

Because transactions occurring automatically are comparatively frictionless, they appear to generate less consumer information. At times, consumers who have inadvertently given preauthorization for payments have not known that the transactions were occurring until they noticed a significant decline in their bank accounts. Likewise, the true cost of the payments is often concealed from consumers: if they are not notified when a transaction takes place, consumers must conduct a personal investigation to discover how frequently payments are occurring, and the size of those payments. This creates strange incentives for sellers, who may benefit from structuring payments and transactions in such a way that they attract little attention or scrutiny from customers. As the examples below will show, sellers have found surprisingly clever means of accomplishing this end.

Nor is this the only way automatic selling distorts seller incentives. As preauthorizing payments reduces the amount of information consumers receive about cost, it may reduce the information they receive about product characteristics as well. Obviously, a consumer who is unaware he or she is buying a good has no impetus to go investigate that good. And after authorization has occurred, the seller has little incentive to communicate with buyers, because it no longer needs to persuade a consumer of a product's worth. In fact, conveying additional product information to the consumer only endangers sales, by running the risk of disrupting an otherwise-stable arrangement!

\section{Obstruction of Consumer Preferences}

Broadly, the ability of markets to allocate resources in a socially optimal manner relies on the ability of market participants to freely express their preferences. If external obstacles are creating costs that constrain the ability of participants to freely transact, the maximum welfare achievable by the market may be reduced.

Fortunately, in most circumstances, market actors have a strong incentive to reduce transaction costs and other obstructions to commerce. When conducting traditional sales, sellers have an incentive to minimize the costs intrinsic to an exchange. Economics 101 tells us that as the price of a good increases at the margin, the quantity sold declines at the margin - and transaction costs increase the effective price a consumer pays without creating concomitant increase in revenue for the seller. In plain English, the harder and more time-consuming it is to complete a purchase, the less people will buy. 
Although a completely frictionless market might have some negative effects for buyers-for example, the information problems described above-efficient exchanges generally benefit consumers as well. Consumers in efficient markets have comparatively more options, because reducing costs effectively increases income. They also face easier economic decisions, in which scarce income is weighed against an expenditure's expected utility, and the effect of external factors such as market structure is minimized. In this way, the incentives of consumers and producers are aligned, to work together in a manner that facilitates negotiation and exchange by reducing transaction costs.

Once again, however, these incentives are disrupted by automatic payment schemes. After preauthorization has occurred, customer inactivity allows a seller to continue to receive payment. A seller, therefore, has a strong incentive to generate obstacles to customer activity. In other words, subsequent to the initial agreement, the seller has an incentive to raise, not lower, transaction costs. Obstacles serving this purpose can take many forms: complex cancellation procedures, pushy customer service representatives, account termination fees, obscure notice requirements, or any other roadblock to easy cancellation. Some obstructions are relatively rigid, while others place only soft pressure on customers. But at a high level of abstraction, they all achieve the same end: increase costs on consumers whose preference is to cancel the series of transactions, reducing the likelihood that the consumers successfully express those preferences.

\section{Ex Ante Uncertainty}

The information and cost problems described above both occur ex post-that is, they both primarily affect incentives and behavior after authorization for automatic selling has been given. Prior to authorization, consumers face a determination not dissimilar from that which occurs in any exchange: they must evaluate a product, evaluate its cost, and choose whether to participate in the exchange. Although certain parameters of the exchange might be unknown, the same is true of virtually any other economic transaction, from the purchase of a used car to the purchase of a breakfast cereal. Nonetheless, consumers who are deciding whether to participate in an automatic selling scheme face a particularly difficult decision, even if they are perfectly rational.

First, the aggregate cost of participating in an automatic selling scheme is very difficult to determine. This is partially because it is contingent on future action by the buyer-namely, the date the buyer chooses to cancel the service. Even a well-intentioned seller offering such a service cannot accurately disclose its total cost, only its initial or periodic cost. This creates, at the outset, a degree of price uncertainty which does not exist in traditional, point-of-transaction exchange, where the full monetary cost is disclosed and (usually) borne at the time of sale. 
But the aggregate cost is contingent on the seller's behavior, as well. If cancelling an automatic selling service is quite easy, then the total cost of subscribing might be low. (Modern advertisers are aware of this-how many television commercials assure prospective customers that their "free trial periods" include "easy cancellation"?) Raise the difficulty of cancellation, however, and the aggregate cost of a subscription might rise. This generates additional uncertainty, because it is unlikely that a customer will know, ex ante, exactly what the cost of cancellation will be.

On top of creating uncertainty about cost, automatic selling exacerbates uncertainty about product utility. In a typical economic transaction, the consumer receives the product at the point of sale, and can therefore rely upon present preferences when weighing its utility. But temporal distance from a purchase complicates this evaluation, because the consumer must assess both the product being offered and his or her own future preferences. Even for a purely rational individual, any estimation of future circumstances includes a probabilistic element-an element that grows more important as the timespan increases. (What's more, as previously discussed, the timespan itself is uncertain, and also must be regarded probabilistically.) Choices about the future are, quite simply, harder to make than choices about the present. Forcing or encouraging a customer to preauthorize his or her transactions generates uncertainty and creates inherent risk of mistake.

Although traditional consumers also face some degree of ex ante uncertainty about cost and utility, the problem is more severe in the context of automatic selling. If all transactions can be understood to fall on a spectrum of complexity, the factors above conspire to push automatic sales arrangements towards the high end of the spectrum, where attempts to evaluate a particular offering might especially tax a consumer's limited cognitive resources.

It is also important to note that the ex post and ex ante risks, though distinct, are interwoven. If consumers could opt out of an agreement to make future payment at no cost, then future uncertainty would be irrelevant-consumers could simply cancel their agreement once the passage of time diminished the uncertainty. But after a preauthorization has occurred, cancelling the agreement will always entail some additional transaction cost-and sellers have a strong incentive to make that cost as high as possible. In turn, the potential difficulty consumers face in extricating themselves from preauthorized payments creates more pressure to make good initial determinations about purchase utility. In short, automatic selling leaves consumers trapped: they must make decisions earlier, while less informed, or later, when they're already ensnared by sellers.

\section{B. Automatic Selling in Today's Marketplace}

Many firms, in many economic sectors, engage in some form of questionable automatic selling. Some, like internet scammers, are small or even unknown, operated in 
the shadows by unscrupulous entrepreneurs; others are large and even prestigious, like AOL. Sometimes, the questionable practices occur alongside robust, traditional business models, like the sale of consumer retail goods or financial products. Very often, automatic sales are in the form of subscriptions.

Frequently, the product or service being sold is not literally valueless so much as the selling is overinclusive, with the effect of creating a customer base which includes genuine buyers, and others who neither need nor want the good in question. Falling into this gray area are many products and services that intermingle properties of traditional commerce and automatic selling; for instance, a consumer may happily subscribe to streaming video service but later find it prove unexpectedly difficult to cancel, or fail to realize that a small subscription warranty plan was quietly tacked onto the sale of a dishwasher.

Data about the scope of automatic selling and preauthorized payment practices is hard to come by, and data about abusive practices is harder still. The ambiguities described above make it difficult to draw a line between "legitimate" services and exploitative practices. Just as many unscrupulous sellers may provide a marginally valuable product, some respected merchants may benefit marginally from automatic selling. Many of the activities which share features under this analysis are not traditionally regarded as having very much in common. Moreover, for obvious reasons, sellers who utilize dubious sales or payment methods are unlikely to publicize their practices, or even fully admit to them.

Nonetheless, some rough statistics do exist. The Automated Clearing House acts as an intermediary for all direct debit transfers in the United States, and uses transaction codes to classify all exchanges. In 2006, it logged 2.4 billion preauthorized commercial debit transactions in its network, totaling over $\$ 1.8$ trillion. ${ }^{12}$ By 2012 , the number of preauthorized debit transactions had grown to 3.1 billion, the overwhelming majority of which remained commercial. ${ }^{13}$ It must be noted, however, that a large percentage of this number is likely accounted for by automatic payments for rent, mortgage, utility bills, and similar expenses, which are among the least objectionable forms of automatic selling. Regardless, the volume of commerce being conducted automatically is tremendous. And this figure excludes preauthorized payments made through credit cards, which pass through other networks, as well as forms of automatic selling which do not rely upon preauthorized payment.

Even in the absence of concrete figures, a handful of case studies can help illustrate the prevalence of automatic selling. Each of examples below has, even in isolation, been

\footnotetext{
${ }^{12}$ National Automated Clearing House Association, 2006 ACH Network Transactions, https://www.nacha.org/userfiles/File/Stats/2006_20ACH_20Network_20Summary.pdf.

${ }^{13}$ National Automated Clearing House Association, Overall ACH Volume Exceeds 21 Billion in 2012, https://www.nacha.org/sites/default/files/files/ACH_Rules/2013\%20Rules\%200ps/Year-End\%202012.pdf.
} 
regarded as severe enough to generate regulatory scrutiny and negative media coverage. Nor are the following examples meant to be in any way comprehensive-indeed, it is probably not possible to provide a comprehensive list of these practices, because so many of them rely on remaining unnoticed by consumers. Nonetheless, they should provide some sense of the scale of the problem.

\section{The FTC Suit Against Jesse Willms}

Automatic selling exists in many contexts, but it thrives online, where acquiescence to lengthy user contracts is the norm, and merchants can easily inundate consumers with "free" offers and other product advertising. Historically, the internet has also been seen as a lightly regulated commercial sphere; it should come as little surprise that many online offers are little more than scams. In recent years, however, some internet merchants' sales practices have attracted regulatory scrutiny. The resultant proceedings reveal preauthorized payment and automatic selling as a major component in the internet scammers' arsenal.

In May of 2011, the Federal Trade Commission filed a major enforcement action against a Canadian resident, Jesse Willms, and ten online companies he controlled. ${ }^{14}$ The FTC's Director of Consumer Protection summed up the charges against Willms and his associates: "The defendants used the lure of a 'free' offer to open an illegal pipeline to consumers' credit card and bank accounts."15 The agency concluded that Willms' gross sales totaled $\$ 467$ million, resulting in "unreimbursed consumer injury" of \$412 million. ${ }^{16}$

Willms' operation took many different forms, but they shared a basic structure. Through "affiliate marketers," he advertised on many major websites-using, among many others, the famous "one weird old trick" banner ad. ${ }^{17}$ Millions of consumers followed the ads to websites owned by Willms. Here, they could be presented with a range of offers. The exact offers varied-the actual products being sold included teeth whiteners, acai berry products for weight loss, colon cleaners, and various health supplements. ${ }^{18}$ Some sites offered services instead: access to government grants, free credit reports, a "penny

\footnotetext{
${ }^{14}$ Federal Trade Commission, FTC Halts Deceptive Practices of Marketer Who Collected \$359 Million Using Bogus 'Free' Trial Offers, http://www.ftc.gov/opa/2012/02/willms.shtm. In bringing its case against Willms, the FTC worked closely with Canadian authorities. Id. Of course, some nations may be less willing to cooperate with US officials in an action against their own resident.

${ }^{15}$ Federal Trade Commission, FTC Charges Online Marketers with Scamming Consumers Out of Hundreds of Millions of Dollars with 'Free' Trial Offers, http://www.ftc.gov/opa/2011/05/jessewillms.shtm.

${ }^{16}$ Amended Complaint at 27, FTC v. Jesse Willms, et al., No. 2:11-cv-8028-MJP (W.D.Wa. 2011), available at http://www.ftc.gov/os/caselist/1023012/110902jwillmscmpt.pdf.

17 Id. at 9; Trine Tsouderos, FTC Cracks Down on Bogus Online News Sites That Are Actually Ads, CHICAGO TRIBUNE, Mar. 22, 2013.

${ }^{18}$ Amended Complaint at 11, FTC v. Jesse Willms, et al..
} 
auction" site where subscribers could bid for consumer goods at apparently cheap prices ${ }^{19}$, and "a work-at-home scheme." 20 Regardless of the good or service in question, the sites attempted to downplay the risk faced by a purchaser. The sites promised "risk-free" trials, free samples, free sign-up bonuses, and special introductory prices-often a dollar. ${ }^{21}$ Up to four million consumers opted to take one or more of these offers. ${ }^{22}$

In order to receive the trial, a consumer first had to enter credit or debit payment information. ${ }^{23}$ The charges were justified in various ways, such as paying the $\$ 1.00$ introductory price, or paying for shipping. ${ }^{24}$ Once they had entered their information, however, consumers were subjected to a withering array of charges. A substantial portion occurred immediately - single payments ranging from $\$ 40$ to $\$ 126.25$ But customers were almost invariably enrolled for one more or automatic recurring payment plans as well. Some of these were "continuity plans," in which the initial purchase was repeated monthly for a fee-generally $\$ 79.95 .^{26}$ Most of the time, as a purported “bonus," customers were also automatically subscribed to various additional, unrelated services. ${ }^{27}$ These services were usually comprised of password access to website; for instance, access to an "Insider Secrets Expert Tips" site or a "Comprehensive Weight Loss" ebook. ${ }^{28}$ Of course, these subscriptions recurred monthly, too.

The behavior of Willms' companies was in many ways typical of a seller relying on a preauthorized payment scheme. As might be expected, the companies did whatever they could to limit the amount of information exchanged during the course of the transaction, and minimize their profile to consumers after preauthorization had occurred. Initial disclosure of these fees, charges, and additional products was universally inadequate. Descriptions of the "bonus" products and the full billing arrangement were buried in fine print, or on another, linked "Terms and Conditions" page. ${ }^{29}$ The disclosures were never in the general vicinity of the box where customers entered their credit card information, and

\footnotetext{
${ }^{19}$ Far from being desirable, participation in a penny auction is almost certain to result in a major loss to a consumer. In a penny auction, bids are capped at a low amount-hence the name-and all bids are retained by the auctioneer. Because previous bids are sunk costs, and the expected value of an additional bid usually exceeds its cost, rational bidders will continue to participate forever, ultimately driving the winning bid far above the value of the auctioned good-and ensuring the losing bidders come away empty-handed and considerably poorer for their efforts.

${ }^{20}$ Amended Complaint at 20-21, FTC v. Jesse Willms, et al.

${ }^{21}$ Id. at 19.

${ }^{22}$ Federal Trade Commission, FTC Halts Deceptive Practices of Marketer Who Collected \$359 Million Using Bogus 'Free' Trial Offers, http://www.ftc.gov/opa/2012/02/willms.shtm.

${ }^{23}$ Amended Complaint at 9, FTC v. Jesse Willms, et al.

${ }^{24}$ Id. at 14.

${ }^{25} \mathrm{ld}$. at 15.

${ }^{26}$ ld. at $9,15$.

${ }^{27}$ Id. at 13-15.

${ }^{28}$ Id. at 12.

${ }^{29}$ Id. at 18.
} 
were visually outmatched by the many mentions of "risk-free" or "trial" offers. ${ }^{30}$ Even in the lengthy fine-print disclosures, the sites avoided mentioned additional fees until halfway through the document. ${ }^{31}$ Willms' companies took other measures to disorient customers, too. For instance, rather than using the tried-and-true strategy of adopting a single, recognizable trademark, company and product names changed constantly. The FTC's complaint lists the following names for weight and health loss products alone: Wuyi Burn, Wuyi Yea, Wuyi Source, Easy Weight Loss Tea, AcaiBurn, AcaiBurn Max, Ultra AcaiBurn, AcaiBurn Plus, AcaiEdge Max, Detox AcaiBurn, Max AcaiBurn, Extreme AcaiBurn, Maximum AcaiBurn, Premium AcaiBurn, AcaiSlim Detox, PureCleanse, PureCleanse Detox, PureCleanse Ultra, Ultimate PureCleanse, Nature PureCleanse, and PureCleanse Max. ${ }^{32}$

And after the transaction had been completed, the companies did their best to maintain a low profile. Knowing that large monthly transactions might attract undue attention from customers, the preauthorized payments were structured as to be innocuous on bank statements. When billing customers for their "bonus" subscriptions, payments were broken into "intentionally odd amounts," such as $\$ 3.24$ or $\$ 7.35$, resembling day-today small purchases. ${ }^{33}$ Billing through the "bonus offers" was generally conducted by a separate, affiliated company, so accountholders scanning through their statement would not immediately associate the charges with the purchase they had made. In its complaint, the FTC notes that customers usually failed to realize that the bonus subscriptions even existed until they noticed the offending charges on their account; indeed, these recurring charges could continue unnoticed even after the customer had taken steps to purge the initial transaction. ${ }^{34}$

Finally, the Willms companies took extensive measures to prevent customers from terminating the transactions after authorization. In order to avoid paying for the "free trial" products or services, and thus to avoid being enrolled in a subscription plan, a customer had to contact the company and return the product before the expiration of a short period. ${ }^{35}$ This ranged from two weeks to a mere twenty-four hours. After the subscription had begun, customers only had a short period each month to cancel their subscription, before the next month's delivery left the warehouse. ${ }^{36}$ Customers attempting to cancel after this point were charged the next month's fee; this would only be returned if a customer sent back the goods and paid the literal transaction costs of shipping, packing,

\footnotetext{
${ }^{30} / d$.

${ }^{31} / d$.

${ }^{32}$ Id. at $11-12$.

${ }^{33} / d$. at 21.

${ }^{34}$ Id.

${ }^{35} / d$. at 20-21.

${ }^{36} / d$.
} 
insurance, and delivery confirmation. ${ }^{37}$ Returns were only accepted if customers had first contacted customer service to receive a cancellation number and a separate identification number. ${ }^{38}$

If the customer had been subscribed to any additional products or services during the course of their initial transaction, these had to be cancelled separately. For each individual subscription, the subscriber needed to locate and call a separate customer support number. ${ }^{39}$ Here, again, customers were subjected to short cancellation periods and draconian refund policies. The FTC noted that customers typically discovered the charges after receiving a monthly account statement, by which point the latest refund period had probably concluded. ${ }^{40}$

Despite all this, Willms and his companies evaded efforts by financial intermediaries to weed out scammers. He held accounts at merchant banks, for the purpose of accepting credit card payments. The transactions described above appeared to violate bank underwriting criteria requiring that accountholders provide adequate disclosure to end customers; when warned of this violation, Willms created "dummy" sites to show the banks. ${ }^{41}$ Unsurprisingly, the transactions conducted by Willms also generated an uncharacteristically high number of chargebacks (as high as $20 \%$ of tranasctions), where customers demand that the credit card company reverse a particular transaction. ${ }^{42}$ This too ran afoul of merchant bank underwriting criteria, but once again, Willms found a workaround. His companies worked to artificially inflate the number of transactions occurring on their accounts, thereby lowing the percentage of chargebacks. ${ }^{43}$ For instance, single transactions were split into multiple transactions, and tiny charges were applied to customer accounts and almost instantaneously retracted. ${ }^{44}$ When all else failed, Willms recruited other individuals to register shell corporations, and continued conducting business under the names of these new entities. ${ }^{45}$ The scam continued undeterred until the FTC finally obtained a settlement order against Willms, imposing a judgment of \$359 million and requiring that he surrender "his bank account funds and ... house, personal property, and corporate assets, including a Cadillac Escalade, fur coat, and artwork." 46

\footnotetext{
${ }^{37}$ Id.

${ }^{38} / d$.

${ }^{39} / d$.

${ }^{40} / d$.

${ }^{41}$ ld. at $25-27$.

${ }^{42} / d$.

${ }^{43} \mathrm{ld}$.

${ }^{44} / d$.

${ }^{45}$ Id.

${ }^{46}$ Federal Trade Commission, FTC Halts Deceptive Practices of Marketer Who Collected \$359 Million Using Bogus 'Free' Trial Offers, http://www.ftc.gov/opa/2012/02/willms.shtm.
} 
The Willms saga starkly illustrates the mechanics of automatic selling, and its potential dangers. Willms and his companies easily evaded the disclosure requirements associated with electronic payment schemes, and tricked millions of consumers into signing up for recurring charges. In accordance with the incentives created by automatic selling schemes, the companies then aggressively pursued strategies for limiting direct contact with consumers, and adopted policies to frustrate cancellation attempts. It was frequently successful, as well-Willms' customers often didn't know they were his customers. And the failed attempts to reign in these practices demonstrate something else about automatic selling schemes: third parties are ill-situated to judge when abusive selling is or is not occurring. Willms' companies were shadowy, fluid entities, and even massive, global payment firms had trouble tracking them down. Although the merchant banks and credit card companies had the capacity to put a halt to unwanted transactions, the topdown private regulatory approach ultimately struggled to differentiate between a scam artist and a legitimate business venture, even while end customers watched their bank accounts drain empty.

\section{Online Credit Reporting}

"It's all because some hacker stole my iden-ti-tee/Now I'm in here every evening serving chowder and iced tea/Should have gone to FreeeeeeCreditReport.com/Could have seen this coming at me like an atom bomb." 47 And with those immortal words, sung in a 2007 commercial by a waiter in a tacky pirate-themed restaurant, FreeCreditReport.com landed in the zeitgeist. The online credit monitoring service's wry, hilarious advertising quickly generated a huge fanbase. ${ }^{48}$ It churned out over a dozen jingles, all telling the same story: a hapless dope was forced to endure working-class ignominies because of his poor credit score.

But there was more to FreeCreditReport.com than met the eye. The site was maintained by Experian Consumer Direct, itself a subsidiary of the credit bureau Experian..$^{49}$ Site visitors could indeed obtain their "free" credit report-provided that they entered credit card information. ${ }^{50}$ Only later did consumers discover that they'd been enrolled in an Experian credit monitoring program, for a recurring monthly charge of $\$ 14.95 .51$

\footnotetext{
${ }^{47}$ FreeCreditReport.com, "Pirate Commercial," available at http://www.youtube.com/watch?v=bnuRLURYqVM.

${ }^{48}$ Helen A.S. Popkin, Sing It, FreeCreditReport.com Guy!, NBC NEws, http://www.nbcnews.com/id/26061279/ns/technology_and_science-tech_and_gadgets/t/sing-itfreecreditreportcom-guy/\#.UYa3HKKG2So.

${ }^{49}$ Stephanie Clifford, The High Cost of a 'Free Credit Report,' N.Y. TIMES, Aug. 4, 2008.

${ }^{50}$ Id.

${ }^{51}$ Id.
} 
Experian's service was not alone; it merely had the highest profile in a crowded market niche. Competing credit report sites included creditscore.com (\$12.95 per month), credit.com ( $\$ 14.95$ per month), creditreport.com ( $\$ 19.95$ per month), myscore.com and freescore.com (both $\$ 29.95$ per month). Many of these websites bore the hallmarks of legitimacy: associations with major credit agencies, or endorsement from public figures. For example, one TV spot for freescore.com featured New York Times financial columnist Ben Stein (and ultimately cost the writer his job). ${ }^{52}$ But this veneer of respectability hid commonalities with internet scammers like Jesse Willms: virtually every one of these services used free or low-cost trial offers to lure consumers into recurring monthly charges, only noted in small print.

FreeCreditReport.com and similar sites have not gone unnoticed by regulators, but direct enforcement actions have proven largely ineffective. In 2005-before the ultrasuccessful musical ads - the FTC filed suit against FreeCreditReport owner Experian for failing to adequately disclose billing arrangements and automatic renewal. The suit settled for $\$ 950,000$ and the industry continued to grow. ${ }^{53}$

Regulators have also attempted to fight back with education and disclosure. The three major credit agencies are each required to offer all consumers a free annual report, available online at AnnualCreditReport.com, and consumer advocates have widely promoted this alternative service. In 2008, the FTC even commissioned two AnnualCreditReport.com ads, patterned after FreeCreditReport's famous campaign, in which a goofily-dressed pub waiter sings listlessly about the dangers of Experian's site. ${ }^{54}$ Congress also intervened directly. The 2009 CARD Act mandated that any service advertising free credit reports include the phrase "This is not the free credit report required by federal law." 55 In 2010, the FTC promulgated regulations requiring additional disclosures on any free credit report website, including a link to AnnualCreditReport.com. ${ }^{56}$

The ads and regulations both flopped. Slate.com's "Ad Report Card" feature lamented that FreeCreditReport.com is a "force of heinous evil," but was forced to admit that the alternative federal songs "kind of suck," and the whole AnnualCreditReport campaign suffered from "severe aesthetic lameness." ${ }^{\prime 2}$ And credit services were unruffled

\footnotetext{
${ }^{52}$ Felix Salmon, Ben Stein Finally Expelled from NY Times, REUTERS, http://blogs.reuters.com/felixsalmon/2009/08/07/ben-stein-finally-expelled-from-ny-times/.

${ }_{53}^{53}$ Federal Trade Commission, Consumerinfo.com Settles FTC Charge, http://www.ftc.gov/opa/2007/02/cic.shtm.

${ }^{54}$ AnnualCreditReport.com, "Restaurant," available at www.youtube.com/watch?v=xZOxsF5XWfo.

5515 U.S.C. $1681 \mathrm{j}(\mathrm{g})$.

${ }^{56}$ Federal Trade Commission, FTC Amends Free Credit Reports Rule to Help Consumers Steer Clear of 'Free' Offers that Cost Money, http://www.ftc.gov/opa/2010/02/facta.shtm.

${ }^{57}$ Seth Stevenson, Credit Crunch, SLATE.COM, http://www.slate.com/articles/business/ad_report_card/2009/04/credit_crunch.html.
} 
by the new FTC rules. Many simply adopted the Willms tactic of charging an initial $\$ 1$ fee. ${ }^{58}$ Technically no longer free, the sites maintained they were not bound by the regulation. (FreeCreditReport and CreditReport.com are especially shameless; in order to receive a score, consumers must "[s]tart by donating \$1 to charity.") ${ }^{59}$ And others - at least 18!ignored the rule outright, in defiance of FTC warnings. ${ }^{60}$ Meanwhile, disclosures of recurring fees remain tiny and easy to overlook. This outcome is disheartening, but perhaps inevitable, so long as regulators were forced to pit their resources against private industry. In 2007 and 2008, FreeCreditReport.com alone had an annual advertising budget of $\$ 70$ million. 61 The FTC's entire 2007 budget was only $\$ 260$ million, and it could allocate a mere $\$ 100,000$ to its ad campaign.62 In this context, even Experian's $\$ 950,000$ penalty is barely an afterthought, leaving the company tens of millions to design clever methods of selling their product despite mandated disclosures.

\section{Gyms and Health Clubs}

Most gyms and health clubs offer memberships in the form of recurring monthly subscriptions. The industry is notorious for its byzantine cancellation procedures-so much so that it came under investigation by the UK's consumer protection agency in March of 2013.63 Virtually all major fitness franchises require that members give at least 30 days notice before terminating a membership. Because most people do not plan to end subscriptions that far in advance, the requirement often serves as a de facto cancellation fee. But companies and franchises are regularly accused of even more troubling practices.

Gold's Gym, one of the largest fitness chains in the world, has accumulated hundreds of complaints on the consumer advocacy site Consumer Affairs, almost all of which focus on the difficulty of cancelling accounts. ${ }^{64}$ The gym "requires a certified letter sent by the United States Post Office in order to officially cancel [a] membership," but is also accused of frequently ignoring the letter, once sent.65 Other obstacles cited include lengthy telephone

\footnotetext{
${ }^{58}$ Felix Salmon, Ben Stein's Employer Breaks the Law, REUTERS, http://blogs.reuters.com/felixsalmon/2010/04/05/ben-steins-employer-breaks-the-law. 
calls, refusals to honor verbal requests to terminate a membership, undisclosed fees, and undisclosed cancellation requirements. 66 The gym often requires customers to complete an extensive cancellation form - and then sometimes delays processing the form (for up to six months!), billing customer accounts all the while. ${ }^{67}$

No major fitness chain fares much better. 24 Hour Fitness, the largest gym in the world by membership, also requires written notice to terminate contracts, and does not allow verbal or telephone cancellations. ${ }^{68}$ It settled a class action lawsuit in 2007 for continuing to collect fees after member cancellations. ${ }^{69}$ Competitor LA Fitness is currently facing a similar suit; its account termination policy allows members to quit at "any time"provided they send written notice to the chain's headquarters in Irvine, California. ${ }^{70}$ During the process, customers might be asked to provide an account number, birth date, physical address of the gym they use, license number, social security number, current address, and a reason for cancellation. (The site also encourages customers to consider "freezing" their contract instead of cancelling it, paying a $\$ 10$ monthly fee for the privilege of putting their membership in limbo. $)^{71}$ The Planet Fitness franchise has also attracted dozens of Consumer Affairs complaints about its cancellation policy. ${ }^{72}$ For instance, customers report that the gym continues to renew subscriptions unless customers can demonstrate they live more than 25 miles from a location, or can prove a medical disability requiring cancellation. ${ }^{73}$

In addition to refusals to honor cancellation requests, gyms and health clubs frequently fail to provide necessary information to customers. Fitness centers use nowfamiliar techniques to entice consumers: free trials that silently morph into expensive, automatically-renewing memberships. Very often, customers only discover that a subscription has not been cancelled when they notice enormous deductions from their bank account, sometimes running into the thousands of dollars. Because the gyms themselves have a history of falsely representing that an active account has been

\footnotetext{
${ }^{66}$ Gold's Gym, Consumer Affairs, http://www.consumeraffairs.com/health_clubs/golds.htm.

${ }^{6}$ Id.

${ }^{68}$ Can I Cancel My Membership?, 24HourFitness.com, http://www.24hourfitness.com/membership/cancel/.

${ }^{69}$ Eric Young, 24 Hour Fitness Settles Class Action Suit, SAN FRANCISCO BusINESS TIMES, July 31, 2007, available at http://www.bizjournals.com/sanfrancisco/stories/2007/07/30/daily15.html?page=all.

${ }^{70}$ Contact Us, LAFitness.com, http://www.lafitness.com/Pages/contactus.aspx.

${ }^{71} / d$.

${ }^{72}$ Planet Fitness, Consumer Affairs, http://www.consumeraffairs.com/health_clubs/planet_fitness.html.

${ }^{73}$ ChrisJC0189, Planet Fitness Complaint, My3Cents.com, http://mythreecents.com/showReview.cgi?id=37639l; Comment by Lindsay of Braintree, MA, Planet Fitness, Consumer Affairs, http://www.consumeraffairs.com/health_clubs/planet_fitness.html.
} 
terminated, subscribers are stuck in the frustrating position of having no easy way to confirm a successful cancellation until the next month's fee is charged. ${ }^{74}$

\section{Newspapers and Magazines}

Of all the subscription services offered to retail consumers, newspapers and magazines have some of the strongest incentives to avoid deceiving consumers. Unlike shady online firms, most publications have a high degree of name recognition (at least within a particular locality). Unlike a franchised local gym, newspapers and magazines have comparatively enormous customer bases, with tens of thousands, hundreds of thousands, or even millions of subscribers. And more than in many industries, a journalistic outfit relies on a strong reputation to stay afloat.

As a result, it's comparatively unusual for newspaper and magazine publishers to deceive or obstruct consumers. But the mechanics of automatic selling and preauthorized payment can result in unwanted sales and consumer harm regardless of whether a vendor aggressively exploits the system. In fact, the periodical publishing industry is an excellent case study in how the mechanics of automatic selling can distort seemingly harmless transactions. Publications generally offer automatically renewing subscriptions. This means that a customer who prefers cancel her subscription is required to bear the transaction cost associated with contacting the company, slightly decreasing the chance that the subscription will be cancelled. And there are a number of small tweaks to the system that can increase that chance. For instance, some publications enable auto-renewal by default, so that a customer may not realize that a renewal is approaching until it is too late. ${ }^{75}$ Others cancel delivery immediately upon termination of a subscription without refunding prior payments, incentivizing customers to delay cancellation until immediately before the next subscription period (and therefore increasing the chances of accidental renewal). ${ }^{76}$ And many periodicals do not give notice that an auto-renewal is approaching, increasing the difficulty of unsubscribing in a timely fashion. ${ }^{77}$ None of these policies is

\footnotetext{
${ }^{74}$ For an example of this sort of complaint, see Ryn Gargulinski, Complaints Against Local Gyms Triple Since 2006, Tucson CitizEN, Jan. 14, 2009, available at http://tucsoncitizen.com/morgue/2009/01/14/107570-complaintsagainst-local-gyms-triple-since-2005/.

${ }^{75}$ Terms and Conditions, FINANCIAL TIMES ("If you have chosen to pay through a continuous billing method such as credit card continuous service or direct debit, then unless you notify us before the end of your Subscription period that you no longer wish to receive your Subscription, your Subscription will renew for another period."), available at http://www.ft.com/cms/9c22cfc8-cda8-11e0-bb4f-00144feabdc0.html.

${ }^{76}$ Premium Subscriber Agreement, BILLBOARD, available at https://subscribe.billboard.com/sub/.

77 Subscriptions, WashingtonPost.com, https://account.washingtonpost.com/acquisition/ ("You will not be notified of upcoming Easy Pay charges. . ."); Subscription Agreement, TIME ("You authorize TIME to charge your credit/debit card or PayPal account at the price above now and in time to renew your TIME subscription, without interruption, before the start of each new annual term at the low subscriber rate then in effect unless you tell us to stop."), available at https://subscription.time.com/storefront/subscribe-to-time/site/td-allaccessweb0711.html?link=1004495.
} 
especially abusive, and all of them might even be disclosed in the initial contract! Nonetheless, their combined effect is to generate customer inertia, and ultimately, harm to consumers.

And as with virtually all automatic selling arrangements, the competing incentives of buyer and seller mean that merchants are rewarded for obstructing their customers, even in small ways. Any obstacle to subscription cancellation improves a periodical's sales at the margin; it's no coincidence that cancellation procedures are usually less clearly disclosed than other account services on a publication's website. Nor is it unusual for a publication which offers many services online-even temporary delivery holds-to require a phone call to effect a permanent cancellation. ${ }^{78}$

There are also significant examples of egregious misbehavior in the industry, as even prestigious publications succumb to the temptations of outright exploitation. In the early 2000s, Time, Inc. was caught renewing subscriptions with clearly insufficient notice, and using threatening debt collection letters to frighten consumers into paying the charges. ${ }^{79}$ It subsequently signed a settlement with 23 state attorney generals, agreeing to reform its renewal practices to protect consumers. ${ }^{80}$

But in March of 2011, the New York Times reported that Time had acquired a subsidiary, Synapse Group, which had then partnered with Condé Nast, Hearst, and other publishers to sell magazine subscriptions. ${ }^{81}$ Despite its affiliation with Time, Synapse was not bound by the prior settlement agreements. ${ }^{82}$ And it was generating millions of subscribers-alongside a flood of consumer complaints. Synapse, naturally, was offering "free trials" which matured into full-price, automatically renewing subscriptions. "Synapse is skilled at signing up subscribers," the Times noted, "but miserable at alerting them later that their subscriptions are being renewed." 83 In an especially insidious twist, its mailed renewal notices seemed to be designed to resemble junk mail, so that customers would throw them out unopened. ${ }^{84}$ And since charges were applied under Synapse's name-not the publisher's or the magazine's - an accidental subscriber was unlikely to figure out was happening until they conducted an independent investigation. One attorney, involved in a lawsuit against Synapse, summed up the company's sales strategy: "The whole game is to

\footnotetext{
${ }^{78}$ Home Delivery Questions, NewsObserver.com, http://support.newsobserver.com/kb/index. php?action=category\&id=2.

79 John D. Solomon, You're Renewed: Like It or Not, AMERICAN JOURNALISM REVIEW, Dec. 2002.

${ }^{80}$ David Segal, How Did This Become a Commitment?, NEW YORK TIMES, Oct. 15, 2011.

${ }^{81} / d$.

${ }^{82} / d$.

${ }^{83} \mathrm{ld}$.

${ }^{84} / d$.
} 
discourage as many as possible from canceling, and these guys are very sophisticated about how they do it." 85

\section{And Much, Much More!}

The abuses accompanying automatic selling are rarely as egregious as those perpetrated by Jesse Willms or FreeCreditReport.com. The problems associated with gym memberships and Synapse Group are probably closer to the norm. In most commercial contexts, automatic selling might occasionally raise an eyebrow, or even cause serious financial harm to a few customers, but does not draw the sustained wrath of federal watchdogs. But if most companies' conduct is less than brazen, it is not necessarily less harmful for consumers. This is because low-key practices may persist for years, causing injury all the while; additionally, the implicit ambiguity of the injury caused makes it difficult for consumers to seek redress. Given enough time, a dripping faucet can cost as much as a broken pipe.

And companies across the economy seem unable to resist the financial drip-feed of automatic selling and preauthorized payment. The entertainment industry increasingly relies upon long-term, automatically-renewing subscription services. Cable television has been around for decades (and generated its fair share of consumer frustration), but streaming video services like Netflix and Hulu have moved film rental into the world of monthly subscriptions. ${ }^{86}$ With Spotify, the music industry has done the same. ${ }^{87}$ Similar trends are clearly visible in the video game industry, which by most estimations dwarfs commercial film and music production. The two highest-grossing video games of all time, World of Warcraft and Call of Duty: Black Ops, both involve subscription services. ${ }^{88}$ The former has maintained over eight million monthly subscribers from $2004,{ }^{89}$ and after the latter broke individual retail sales records, its publisher promptly announced the creation of an "Elite" subscription service, which provide perks for online players in between franchise installments. ${ }^{90}$

The telecommunications industry often incorporates automatic renewal clauses into contracts for phone and internet service, to such an extent that a number of states attempt

\footnotetext{
${ }^{85} / d$.

${ }^{86}$ Graeme McMillan, Viewers Are Flocking to Streaming Video Content-And So Are Advertisers, WIRED, http://www.wired.com/underwire/2013/03/streaming-video-advertising/.

87 I Dreamed a Stream, THE ECONOMIST, June 15, 2013.

${ }^{88}$ Ana Douglas, Here Are the 10 Highest Grossing Video Games Ever, BUSINESS INSIDER, http://www.businessinsider.com/here-are-the-top-10-highest-grossing-video-games-of-all-time-2012-6?op=1.

${ }^{89}$ World of Warcraft Subscriber Numbers, JoYstIQ, http://wow.joystiq.com/tag/subscriber-numbers/.

${ }^{90}$ Brian Ashcraft, One Million People Are Paying for Call of Duty Elite, KoTAKU, http://kotaku.com/5861763/onemillion-people-are-paying-for-call-of-duty-elite.
} 
(apparently with little success) to regulate the use of these clauses. ${ }^{91}$ Telecom providers have developed a number of strategies unavailable to subscription services with a static price. By placing limits on the periodic use of services-e.g., a certain number of longdistance minutes, monthly data plans with download caps-providers are able to engage in a discreet form of negative-option billing. Customers who exceed the predetermined limits are considered to have acquiesced to additional sales, and are billed accordingly. As with all automatic selling, the conflicted incentives of buyer and seller are visible here. Phone and internet providers have been criticized for not providing customers sufficient notice when approaching caps, essentially pitting customers' mental bookkeeping against merchants' actual bookkeeping. ${ }^{92}$ Likewise, providers have accused of choosing limits that will create uncertainty for a comparatively large number of customers. ${ }^{93}$

But subscriptions aren't limited to nontangible services: unwary consumers can find themselves buying, in automatic monthly installments, DVDs, books, canned pickles, cigars, dietary supplements, golf balls, puzzles and a plethora of other goods that seem likely to end up paperweights. ${ }^{94}$ (Almost predictably, you can also subscribe to an actual paperweight-of-the-month club.) ${ }^{95}$

Back on the shadier side of the economy, automatic selling and preauthorized payment are frequently used in the financial exploitation of seniors. The FBI's guide to senior citizen fraud points to a number of characteristics that make the elderly ideal targets for automatic selling schemes: substantial accumulated savings; increased interest in products improving health, security, or financial stability; an unwillingness to report exploitation; lowered cognitive ability resulting in less ability to remember or undo harmful arrangements; and a tendency to trust sellers, which is particularly dangerous on the telephone or internet. ${ }^{96}$ As a result, seniors may be comparatively easy to recruit into monthly product clubs selling dubious health supplements, commemorative collectors' coins as "investments," and other items. And sellers have developed more sophisticated means of exploiting seniors' consumer tendencies. For instance, some firms make unsolicited calls to elderly citizens and offer a monthly subscription to a "theft monitoring

\footnotetext{
${ }^{91}$ Contract Auto-Renewals Not Necessarily So "Automatic" as Recent NY Case Demonstrates, NGELaw.com, http://www.ngelaw.com/Contract-Auto-Renewals-Not-Necessarily-So-Automatic-as-Recent-NY-CaseDemonstrates.

92 Mike Masnick, The Stupidity of Data Caps: No One Knows What a Megabyte Is, TECHDIRT, http://www.techdirt.com/articles/20120411/20511618460/stupidity-data-caps-no-one-knows-what-megabyteis.shtml.

${ }^{93}$ Felix Salmon, Why AT\&T Is Evil to Have Multiple Data Plans, REUTERS, http://blogs.reuters.com/felixsalmon/2010/06/03/why-att-is-evil-to-have-multiple-data-plans/.

${ }^{94}$ A smattering of monthly product clubs can be seen at www.monthlyclubs.com (beer, wine, cheese, cigars), www.monthclubstore.com (pickles, jelly, potato chips, puzzles, golf balls) , www.joinbomc.com (books), www.jackedpack.com (workout supplements).

95 Paperweight of the Month, OBJECTS OF ENVY, http://www.objectsofenvy.com/caiu000-master.html.

${ }^{96}$ Federal Bureau of Investigation, Fraud Target: Senior Citizens, http://www.fbi.gov/scams-safety/fraud/seniors.
} 
service"; in reality, the senior is simply sent a set of identification stickers to place on valuables, supposedly to facilitate police recovery.

And the list goes on. Scholastic, the children's bookseller, was fined by the FTC for delivering unwanted books, and then billing for them, as an undisclosed part of a children's book club. ${ }^{97}$ Home security alarm services are often the subject of complaints for refusing to cancel customer accounts. ${ }^{98}$ On ConsumerAffairs.com, online dating websites have received hundreds of complaints for similar practices. ${ }^{99}$ And while there is simply no way to know for sure, one can't help but suspect that harmful billing arrangements are widespread among the thousands of small, local firms providing services to consumers around the country, firms which can blink in and out of existence in a heartbeat and will never face a federal investigation.

Abuse of automatic billing is so ubiquitous that it might have created a small market niche. Enter CancelWizard.com, a website listing over 150 common gyms, telecom providers, magazines, social networks, and credit reports with "abusive" cancellation policies. And if a customer is forlorn at the prospect of spending hours hounding one of these merchants, he can simply pay CancelWizard a one-time fee of $\$ 34.95$ to have it do battle in his stead.

CancelWizard might be a legitimate service, or it might be a scam. No one seems to know for sure, and it exists in economic sphere rife with fraud. ${ }^{100}$ Nonetheless, the site's Frequently Asked Questions section contains a strangely poignant passage:

Once in a while someone will submit an order to cancel "everything". Although we get a good laugh when this happens, we can't cancel every account you have. Our service is meant for the abusive companies that make it hard for you to cancel. ${ }^{101}$

In a truly free market, economic activity is based on mutual assent by economic actors. A truly free market shouldn't generate this kind of frustration. If consumers want to cancel everything-to stop paying for things they don't want-shouldn't they be able to?

\footnotetext{
${ }^{97}$ Federal Trade Commission, Children's Book Publisher to Pay $\$ 710,000$ to Settle Charges It Violated Commission's Negative Option and Telemarketing Sales Rule, http://www.ftc.gov/opa/2005/06/scholastic.shtm.

98 David Segal, Trying to Turn Off a Home Alarm Contract, NEW YORK TIMES, July 25, 2009.

99 Dating Services, CONSUMER AfFAIRS, http://www.consumeraffairs.com/dating_services/index.html.

${ }^{100}$ CancelWizard lists no physical address and information elsewhere suggests that site is being run out of a private residence in Arizona - though, given the nature of its services, this is not entirely implausible. Domain ownership searches also reveal that the site is using a proxy, which helps hide the owners' real identity. On the other hand, there appear to be no online complaints about fraudulent activity, and the Better Business Bureau has collected one positive review of the site's services. Cancel Wizard, Arizona Better Business Bureau, http://www.bbb.org/central-northern-western-arizona/business-reviews/internet-services/cancelwizard-intempe-az-1000014870.

${ }^{101}$ Frequently Asked Questions, CancelWizard.com, http://cancelwizard.com/faq.
} 


\section{CURRENT REGULATION OF AUTOMATIC SELLING}

One does not need to conduct a detailed investigation into regulations affecting automatic selling to deem them wholly insufficient-the prevalence of the practice throughout the economy is more than enough to condemn current consumer protections. Nonetheless, the specific shortcomings of extant regulatory regimes help point the way towards a more sustainable, reliable solution. In the United States, automatic selling and preauthorized payment are largely constrained by three institutional factors-federal agencies, public and private payment card regulation, and state law-each of which is defective in unique ways.

\section{A. The CFPB and the FTC}

At present, two large federal regulators have broad authority to investigate and respond to abusive sales practices targeted at retail consumers: the Consumer Financial Protection Bureau and the Federal Trade Commission. It remains to be seen how, or if, the CFPB will address automatic selling and preauthorized payment schemes. While it has taken an interest in the regulation of payment systems, it has not addressed the wider field of abusive practices related to automated transactions. The agency, of course, is still very young, and its methods are still under development.

The FTC, however, has actively pursued a number of lawsuits and enforcement actions against abusive automated transactions. These have been undertaken as part of its statutory mandate to prevent "unfair or deceptive acts or practices in or affecting commerce."102 The FTC's regulatory method has a number of significant weaknesses. These weaknesses, rather than arising from any unique deficiency of the agency, are the product of its structure and statutory agenda, and therefore could be expected to hinder any regulator with a similar mandate and enforcement approach.

The FTC, while often successful in squelching unscrupulous merchants that have caught its ire, is hamstrung by its litigation-oriented approach. Simply put, the FTC must actively enforce its rules, and it must do so against specific, individual sellers. ${ }^{103}$ As a result, its actions are generally targeted at large-scale offenders, and are often pursued piecemeal against a single enterprise. To put a stop to a sales practice, the FTC must first identify the practice, identify the seller or sellers participating in the practice, and then build a

\footnotetext{
10215 USC § 45(a).

${ }^{103}$ For a discussion of the FTC's enforcement arsenal in the consumer protection realm, see Roscoe B. Starek, III, Protecting the Consumer in the Global Marketplace, June 25, 1997, Federal Trade Commission, available at http://www.ftc.gov/speeches/starek/antwefin.shtm.
} 
sufficient case against each as to obtain a settlement or file a successful lawsuit. The FTC's impact on the market at large is limited to the deterrent effect of its enforcement action. ${ }^{104}$

The FTC's approach is unlikely to have much impact on certain subsets of the market. Many merchants are small or obscure enough to not face much risk of attracting the scrutiny of a single national regulator. Moreover, even among large firms, sellers may be willing to risk practices that are questionable but not clearly abusive, especially if the practice is profitable. The FTC, after all, has more important things to do than track down every subscription plan which proves obnoxious to cancel.

Additionally, the active enforcement approach represented by the FTC is potentially taxing on regulators. Its benefits are effectively capped by available regulatory resources. Regulators have to expend resources actively surveying the market for violators, and then expend even more pursuing enforcement against those violators. Without money and personnel, oversight vanishes.

The resource problem is exacerbated by the breadth of the FTC's mandate. Rather than focusing on a single industry, region, market, or subject matter, the agency broadly targets virtually all sectors of and participants in the US economy. It is essentially empowered to regulate the entire commercial existence of any US firm--advertising and marketing, retail and commercial buying and selling, and antitrust problems. As a result, even significant industries might be surveyed by small teams-such as when, in 2012, a government watchdog discovered that the Mobile Technology Unit, which oversees the massive cellular communications field, contained all of six employees. ${ }^{105}$

Finally, the FTC's active enforcement risks burdening regulated entities, which in turn creates social costs and engenders hostility. This is problem shared with virtually all direct regulation of market participants. Regulation requires information, which in turn imposes costs on producers and consumers, who either must comply with reporting requirements, periodically endure investigations, or actively report violations. Enforcement frequently pits the regulator directly against producers, generating political backlash against the regulation itself. The regulator risks becoming a third entity in the marketplace, neither buyer nor seller, but a chaotic agent undermining the orderly completion of market transactions.

\footnotetext{
${ }^{104}$ For instance, in a response to claims that it had underemphasized cellular and mobile internet commerce in its regulation, the FTC argued that "[its] enforcement actions have created strong incentives for companies of all sizes to secure data [and] respect consumers' choices." Devin Coldewey, FTC's Ability to Thwart Online Deception Extremely Limited, NBCNews.com, http://www.nbcnews.com/technology/ftcs-ability-thwart-online-deceptionextremely-limited-report-852493.

${ }^{105}$ Peter Maass, How a Lone Grad Student Scooped the Government and What It Means for Your Online Privacy, PROPUBLICA, http://www.propublica.org/article/how-a-grad-student-scooped-the-ftc-and-what-it-means-for-youronline-privac.
} 


\section{B. Payment Card Regulation}

As previously discussed, preauthorized payment schemes are heavily reliant on electronic payment methods, and in particular, payment cards. Payment card regulation therefore has the ability to heavily impact these sales techniques.

Empirical evidence suggests that consumers tend to use credit and debit cards in a broadly similar fashion. ${ }^{106}$ This makes sense-these days, both methods function more-orless identically at the point of transaction. Nonetheless, payment regulation rarely recognizes this functional equivalence. Instead, each method is subject to very different sets of rules. Direct debits to and from a consumer account-e.g., debit cards-are governed by the Electronic Funds Transfer Act (EFTA), which includes rules constraining preauthorized payments. By contrast, credit cards are subject to the Truth-In-Lending Act (TILA), which does not. As a result, recurring credit card transactions are shaped by private rules and guidelines designed by financial intermediaries.

\section{Debit Cards}

EFTA is implemented by the Federal Reserve Board's Regulation E. Under Regulation E, a preauthorized transfer is "an electronic fund transfer authorized in advance to recur at substantially regular intervals." 107 In order to conduct a preauthorized transfer out of an account, the accountholder must provide the financial intermediary with written authorization (which includes electronic signatures). ${ }^{108}$ The accountholder can then stop payment by notifying the intermediary at least three business days in advance of the transfer. ${ }^{109}$

The rule contains an assortment of notice requirements for transfers of funds into a consumer's account. By contrast, when a consumer provides authorization that funds be withdrawn from an account, Regulation E only requires that the payment recipient or financial institution provide notice if the amount varies from the previous transfer, or the preauthorized amount. ${ }^{110}$ This notice must be given at least ten days before the date of transfer. ${ }^{111}$ Alternatively, with a consumer's consent, merchants or financial institutions

\footnotetext{
${ }^{106}$ For instance, one study of grocery purchase data showed that consumers use payments cards -credit and debit alike-more frequently as the amount of the transaction increases. Elizabeth Klee, How People Pay: Evidence from Grocery Store Data, 55 JouRnal of MonetARY Economics 526 (2008). Divergent trends in credit and debit use seem to be the product of demographic characteristics of consumers, not the transactional context-probably because wealthier consumers simply have better access to credit. Id.; Sergei Koulayev, Marc Rysman, Scott Schuh \& Joanna Stavins, Explaining Adoption and Use of Payment Instruments by U.S. Consumers, Federal Reserve Bank of Boston, Working Paper 12-14 (2013).

10712 CFR § 205.2 (k).

10812 CFR § 205.10 (b).

10912 CFR § 205.10 (c).

11012 CFR § 205.10 (d)(1).

${ }^{111}$ Id.
} 
are permitted to only provide notice when withdrawals fall outside a predetermined range. 112

Regulation E's attempt to regulate preauthorized payments suffers from several defects. Virtually all of its protections are contingent upon the sufficiency of the initial notice and authorization; a consumer who unwittingly authorizes payments may receive no additional warning about regular fund withdrawals. Even the notice requirements attached to variable withdrawals are essentially toothless, because they can be signed away when initial authorization is obtained. And the rules exhibit another serious flaw, one that is less immediately apparent. In all cases, it requires that notice be provided by "the designated payee or the financial institution," effectively splitting responsibility for compliance between two loosely-affiliated, dissimilar parties. ${ }^{113}$

\section{Credit Cards}

The federal government has taken essentially no action to address recurring charges on credit cards. The Office of the Comptroller of the Currency's Frequently Asked Questions page, which ostensibly provides consumer-oriented advice on common credit card issues, demonstrates regulators' laissez faire attitude toward the problem. ${ }^{114}$ One question neatly sums up the pitfalls of preauthorized payment: "I cancelled a product after the free trial period, but the merchant keeps charging my credit card account each month. The bank says to resolve it with the merchant. What should I do?"115 The OCC's response merely echoes the bank. It instructs consumers first to write the merchant, and secondarily to contact the bank to dispute any charges that are in error. Amazingly, the site's only other guidance on preauthorized charges is even less helpful. It addresses a consumer who closes his credit card account, only to discover that preauthorized charges are still being applied. The OCC notes that while a cardholder can request a stop on individual preauthorized payments, banks may continue to allow recurring charges until the consumer "submit[s] written confirmation that [he has] cancelled the agreement with the merchant." 116

The credit card market, however, is almost completely dominated by a quadrumvirate of international payment processing firms-Visa, MasterCard, American Express, and Discover-with MasterCard and Visa alone processing nearly $90 \%$ of global

\footnotetext{
11212 CFR $\$ 205.10$ (d)(2).

11312 CFR $\S 205.10$ (d) (emphasis added).

114 Office of the Comptroller of the Currency, Answers About Pre-Authorized Credit Card Payments, http://www.helpwithmybank.gov/get-answers/credit-cards/pre-authorized-payments/credit-cards-preauthorizedpayments-quesindx.html.

${ }^{115}$ Id.

${ }^{116}$ Id.
} 
credit card purchase transactions. ${ }^{117}$ As a result, these companies' private rules for merchants and banks serve as de facto regulation, affecting the payment card market to a degree that rivals or even surpasses American domestic law.

During a credit card payment, information about the transaction is routed through the processing firm, which authenticates the card and contacts the merchant's bank. 118 This information is accompanied by transaction "codes," which identify key features of the transaction. Both Visa and MasterCard recognize a separate category of "card-absent" transactions, which includes special codes for recurring, preauthorized transfers. ${ }^{119}$ Because the firms can identify these transactions as they occur, they can also attach some additional rules to them. For instance, MasterCard requires that the card issuer's response to the merchant include a "merchant advice code" when denying a recurring transaction, so that the merchant and cardholder can determine how to proceed.120 Visa's rules go slightly further, requiring that the initial sales receipt include the phrase "recurring transaction," and information about the frequency and duration of charges. ${ }^{121}$

But once a transaction is validly authenticated, the payment processing firms have exhibited little interest in interfering with its continuation. MasterCard's post-transaction rules seem especially disconnected from reality, blithely reminding cardholders to ensure that merchants retain a written copy of the payment agreement, and instructing merchants not to deliver products after a card has been cancelled.122 And Visa appears to have no special post-transaction rules, instead providing merchants with a handful of recommendations about recordkeeping and consumer notice. ${ }^{123}$

Indeed, both Visa and MasterCard heavily promote their automatic billing services to merchants, with websites and marketing materials that trumpet the virtues of preauthorized transactions. They facilitate the creation of recurring fee arrangements by publishing guidelines and "best practices" pamphlets, which are neither binding nor particularly detailed, and mostly boil down to advice that merchants respond quickly to

\footnotetext{
${ }^{117}$ Purchase Transactions on Global Cards 2011, NILSON REPORT, available at http://www.nilsonreport.com/publication_chart_and_graphs_archive.php?1=1\&year=2012.

${ }^{118}$ For a very brief explanation of the transactional mechanics of a credit card payment, see MasterCard, The Anatomy of a Transaction, http://www.mastercard.com/us/company/en/docs/The_Anatomy_of_a_Transaction_031309.pdf.

119 MasterCard, MasterCard Rules, http://www.mastercard.com/us/merchant/pdf/BM-Entire_Manual_public.pdf; Visa, Card Acceptance Guidelines for Visa Merchants, http://usa.visa.com/download/merchants/card-acceptanceguidelines-for-visa-merchants.pdf.

${ }^{120}$ MasterCard, MasterCard Rules.

${ }^{121}$ Visa, Card Acceptance Guidelines for Visa Merchants.

122 MasterCard, MasterCard Rules.

${ }^{123}$ Visa, Card Acceptance Guidelines for Visa Merchants.
} 
consumer complaints. ${ }^{124}$ Nowhere is it acknowledged that the inbuilt characteristics of preauthorized payments might be driving consumer complaints in the first place. The other focus of the material is marketing-both marketing automatic billing to merchants, and suggestions for merchants who want to market automatic billing to consumers. ${ }^{125}$

Why would card processing firms heavily promote automatic selling? Easilyabused sales practices seem anathema to a business model built on global reputations for security and reliability. At worst, one might expect payment intermediaries to remain agnostic about the structure of the transactions being processed. There are several plausible explanations for this apparent disconnect. Most obviously, preauthorization might increase margins by reducing expenses associated with repeated card verification. Additionally, competition might be preventing firms from taking a more consumer-friendly approach. Visa and MasterCard, in particular, are competing heavily in both the credit and debit card markets, and the industry closely follows even short-term trends in card ownership and usage. ${ }^{126}$ Just as preauthorized payments create a relatively reliable stream of income for merchants, they create a reliable stream of transactions for the payment firms. If either company sought to unilaterally limit these arrangements, its market share would likely decline. But whatever the explanation, it seems clear that private firms do not currently have sufficient incentive to address potential abuse, even if doing so would produce goodwill among cardholders.

\section{State and Judicial Remedies}

While regulation of payment systems is largely a federal endeavor, the FTC's regulation of "unfair or deceptive" business practices shares significant jurisdictional overlap with state statutory and common-law rules. Although state rules do not apply to transactions outside the state's jurisdiction, nationwide companies may still feel the need to bring their business methods into compliance with all state law, giving local rules national effect. This is doubly true of laws adopted by large states home to many customers and firms, such as New York or California.

Many state codes contain laws limiting the use of automatic renewal provisions in contracts with individual consumers (though generally not companies). ${ }^{127}$ These can take several forms. Some states require "clear and conspicuous" disclosure of renewal terms in

\footnotetext{
${ }^{124}$ For one example, see Visa, Bill Pay Marketing Resource Guide for Billers, http://usa.visa.com/download/merchants/merchant-marketing-resource-guide.pdf. 125 Id.

${ }^{126}$ For instance, the Nilson Report publishes a monthly newsletter monitoring card purchase trends. Newsletter Archive, NILSON REPORT, http://www.nilsonreport.com/publication_newsletter_archive.php.

${ }^{127}$ Contract Auto-Renewals Not Necessarily So "Automatic" as Recent NY Case Demonstrates, NGELaw.com, http://www.ngelaw.com/Contract-Auto-Renewals-Not-Necessarily-So-Automatic-as-Recent-NY-CaseDemonstrates.
} 
the initial contract, while others also require notice be given to a consumer in advance of a cancellation deadline. ${ }^{128}$ Sometimes, these requirements are restricted to specific industries with a history of abuse (e.g., gyms, home security, and telecommunications). ${ }^{129}$

The New York code, which has relatively broad restrictions, helps illustrate how these laws function, and how they fail. In New York, a customer with a "contract for service" must be notified of an impending renewal no more than 30 and no less than 15 days in advance. ${ }^{130}$ If notice is not provided, then the renewed contract is unenforceable. ${ }^{131}$ This provision, however, contains an exception for contracts with a renewal period of one month or less, and therefore does not apply to many consumer retail products. ${ }^{132}$ Nor does it specify any particular cancellation procedure, or otherwise ensure that a notified consumer will be able to cancel with ease.

At least one recent case in New York's highest court suggests the state requirement's impact on commerce may be limited. In it, Bloomberg L.P. failed to notify a customer of the automatic two-year renewal of a contract to provide a real-time financial information terminal, worth $\$ 18,720$ per year. ${ }^{133}$ When the customer attempted to cancel after the automatic renewal, Bloomberg insisted, in flagrant violation of New York's statutory requirements, that he pay a full year's payment as an "early termination buyout," plus additional collection fees. ${ }^{134}$ After repeated attempts to collect payment, the customer filed a class action lawsuit against Bloomberg. But when Bloomberg waived all fees, the New York Court of Appeals dismissed the case, claiming that there was no justiciable controversy. ${ }^{135}$ While the outcome suggests that New York's notice requirements are alive and well, the facts also demonstrate that, until the courts are involved, even sophisticated sellers feel little compunction about ignoring those requirements and squeezing subscribers for cash.

\section{FIXING AUTOMATIC SELLING: THE AUTHORIZATION CATALOGUE}

The key to effectively regulating automatic selling and preauthorized payment is to recognize the true source of the harm they cause. As both the theoretical model and the real-world examples demonstrate, automatic selling creates consumer injury by distorting merchant incentives with regards to two key activities: providing information and minimizing obstructions. As a result, consumers often lack the necessary information to

\footnotetext{
128 Id.

129 Id

${ }^{130}$ N.Y. Code § 5-903 (2).

${ }^{131}$ Id.

${ }^{132}$ N.Y. Code $\S 5-903(3)$.

${ }^{133}$ Ovitz v. Bloomberg, L.P., 967, N.Y.3d 753, 756-57 (2012).

${ }^{134}$ Id. at 757.

${ }^{135}$ Id. at $758-60$.
} 
properly evaluate the costs of their participation in an ongoing transaction, up to and including information about whether they are participating in the first place. And even informed consumers often find the process of quitting the transaction burdensome and costly. These problems, in turn, increase the importance of a consumer's initial decision to enter into an automatic selling arrangement, and consequently exacerbate the harms caused by uncertainty over product value and cost.

Previous regulatory solutions have attempted to address the problems caused automatic selling in various ways, but most do so by specifically targeting unscrupulous merchants or attempting, ex ante, to prevent the formation of harmful automatic selling arrangements. This paper proposes a simpler alternative approach: rather than preventing automatic selling from occurring, regulators should change its transactional context. If both the information and obstruction problems can be minimized, the harms associated with automatic selling will shrink, even if the practice itself continues. This "soft-touch" regulatory technique preserves the ability of private actors to easily create and maintain preauthorized payment arrangements where it is useful, but eliminates the ability of abusive merchants to exploit of the unique features of these arrangements to extract wealth against consumers' wishes.

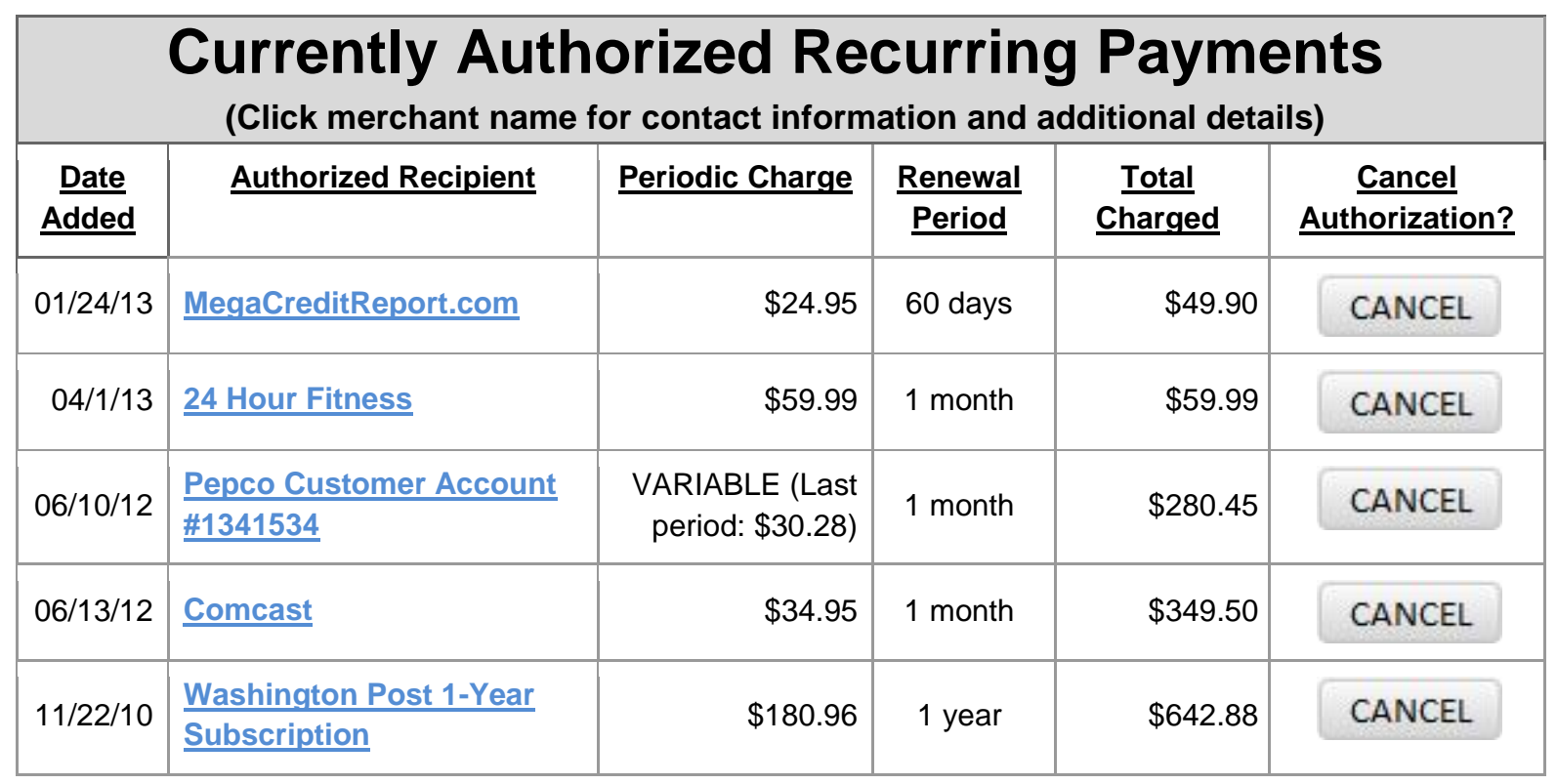

Fig. 1: The Authorization Catalogue

\section{A. The Proposed Payment System}

This paper proposes to address automatic selling by introducing an "authorization catalogue" - a system, similar to a bank statement, through which consumers can manage authorized recurring payments. The system has two primary elements: the catalogue and 
one-button cancellation. The first seeks to resolve the information problem, and the second seeks to resolve the obstruction problem. Both are implemented by financial intermediaries instead of imposed on merchants, and are built off of the current payment architecture.

\section{The Catalogue}

First, banks and other electronic payment intermediaries should provide an easilyaccessible, easy-to-comprehend, and prominently-displayed catalogue of current "open" authorizations and their terms. The catalogue allows consumers to, at a glance, determine the charges they are periodically incurring, reducing the information problem. Since current debit and credit payment rules require intermediaries to identify preauthorized charges, intermediaries would not be forced to collect more information about transactions than they do presently-only to display that information in a systematic way.

The mechanics of the catalogue are simple. Whenever the financial intermediaries receive notice from a merchant that a customer has preauthorized payments from his or her account, the intermediary must add the information on the notice to the catalogue. This should, of course, include the merchant's name, the amount, period, and the date of the authorization. If the amount or timing of the preauthorized charges are flexible-e.g., they are contingent on future events - the maximum charge should be noted, and the charge's contingent nature. Finally, it should include the total amount paid under that authorization so far. Additional information should probably be omitted from the catalogue, to avoid overwhelming the consumer with irrelevant data. If, however, the catalogue is provided digitally, the customer should able to click on each entry for any additional information.

The catalogue would likely look something like an account statement. Another analogue is the installed program registry provided by most modern computer operating systems. This registry serves a similar purpose: informing the user of all currently installed applications, so the user is spared the effort of finding them individually.

Although these details might refined over time, the catalogue's specific appearance and layout should be designed by regulators. Although this runs the risk of stifling innovation by the financial intermediaries themselves, that risk is outweighed by the benefits of a universal design. Consumers would be able to rely on a consistent format when moving from one financial intermediary to the next. Moreover, this would minimize the opportunity for gaming by private actors. Finally, because the catalogue's function is basic and straightforward, the expense of designing it should be minimal.

The catalogue should be easy to access. This is particularly important because the customers most susceptible to abusive preauthorized payments are probably those who do not closely monitor their payment history. Most obviously, intermediaries should be 
required to clearly link to it on their websites, with at least the same prominence as the customer's transaction history. In addition, banks with their own network of ATMs should provide the catalogue via the ATM, in the same fashion that ATMs can be used to view account histories and balance statements. Finally, banks should be required to mail a paper copy of the catalogue to customers every month, alongside the bank statement.

\section{One-Click Cancellation}

Second, presented alongside the catalogue, customers should have the option to immediately, without condition, close any open payment authorization, preferably with "one click" or the equivalent. This allows customers to cancel preauthorized payments with minimal cost or effort, reducing the obstruction problem.

Once again, the system can be analogized to the installed program registry in operating systems. The registry lets users conveniently remove programs without sifting through the file architecture for the program's files; one-click cancellation lets customers cancel payment without tracking down the relevant information for banks or individual merchants.

Regulators should require banks and other intermediaries to immediately honor all closed authorizations. If money leaves a customer's account after the authorization closes, the intermediaries themselves should be liable for the expense, and required to automatically reimburse the customer.

Of course, cancelling the authorization through the intermediary does not immediately impact the seller. For instance, many sellers in preauthorized payment arrangements charge the customer at the end of each billing period. A seller whose authorization has been retracted may not discover that fact until the product had been delivered or the service had been rendered.

But one-click cancellation has several indirect impacts on sellers. In the immediate term, it requires that they approach the customer to receive any payment for which they are contractually due. Customers approached in this way are unlikely to reenter arrangements with unscrupulous sellers. Also, even if the seller convinces a customer to complete his or her payments, those payments, if conducted electronically, would be subject to the same restrictions as they were previously. Try as they might, sellers cannot eliminate the consumer's ability to easily and freely opt out of preauthorized transactions.

Ideally, this would in turn have a long-term impact on sellers. They would have a strong incentive to structure transactions in such a way as to minimize the risk of nonpayment. For instance, payments could be charged at the time a service is rendered or product delivered, rather than after. 
Of course, front-loading payments may not always be an option-for instance, some utilities may not know what to charge a customer until after the billing period. But this is not an insurmountable obstacle. Sellers who must charge at the completion of the billing period can instead simply take a deposit, and return whatever is owed to the consumer afterwards. Such an arrangement would accomplish the same objective as post-sale billing, but has several salutary effects: it informs consumers upfront of the potential costs; in the process, it creates competitive pressure to reduce contingent fees. On the other hand, if a seller feels that the deposit arrangement is too unwieldy, or potential future charges are too unpredictable to be adequately satisfied by a deposit, it can charge at the end of the billing period and simply face a small risk of nonpayment instead. Forcing sellers to make this decision may seem problematic, until one realizes that the current system also contains risks created by unpredictable future charges and non-synchronous transactions. In the current system, however, these risks are usually borne by consumers, rather than relatively sophisticated merchants.

It is possible, however, that one-click cancellation would prevent the use of some currently extant billing arrangements. It is imperative that the inability of merchants to exactly replicate current fee arrangements not be regarded as a critique of the proposed system. ${ }^{136}$ Indeed, it is precisely this inability to create certain potentially-abusive arrangements that is at the very heart of the proposal. The catalogue-and-cancellation system is intended to provide significant flexibility in structuring payments; the areas in which it is relatively inflexible are rigid for a reason. A regulatory solution in which no one is forced to modify their behavior probably fixes nothing.

\section{B. Implementation}

The Consumer Financial Protection Bureau has been given broad rulemaking discretion over consumer financial products. Even without a congressional grant of authority, it likely has the ability to require the use of the authorization catalogue for credit and debit products alike.

The Dodd-Frank Act transferred to the CFPB all consumer protection functions of the Board of Governors of the Federal Reserve, the OCC, the Office of Thrift Supervision, the FDIC, the FTC, the National Credit Union Administration, and the Department of Housing and Urban Development. ${ }^{137}$ This includes rulemaking authority derived from the

\footnotetext{
${ }^{136}$ There nonetheless may be some unusual and unforeseen situations in which providing customers the ability to cancel authorization through the intermediary is undesirable as a matter of policy. These situations should be clearly delineated in advance. When the seller sends the intermediary authorization for such an arrangement, it should include clear instructions on how and when the authorization can be cancelled. This class of authorization should be highlighted in the catalogue, and the seller's instructions should be provided in lieu of a cancellation button. With that said, this exceptional case ought to be very rare, and may not exist at all.

${ }^{137} 12$ USC $\S 5581$ (b).
} 
Electronic Funds Transfer Act (EFTA) and Truth In Lending Act (TILA). Rules promulgated under EFTA "may contain such classifications, differentiations, or other provisions ... for any class of electronic fund transfers ... as in the judgment of the [CFPB] are necessary or proper to effectuate the purposes of this title."138 For instance, the CFPB could issue rules applying specifically to preauthorized debits from an account. The Act allows the Bureau to promulgate rules for documentation of electronic funds transfers, and rules implementing the notification requirements attached to preauthorized transfers. ${ }^{139}$ Meanwhile, TILA contains a similarly deferential rulemaking clause: its section on disclosure guideline allows the CFPB to "prescribe regulations to carry out the purposes of this subchapter," which may contain "additional requirements" that "in the judgment of the Bureau are necessary or proper to effectuate the purposes of this subchapter, to prevent circumvention or evasion thereof, or to facilitate compliance therewith." ${ }^{140}$

Additionally, the authorization catalogue satisfies the CFPB's statutory mandate. Upon its creation, the agency was tasked with ensuring that "consumers are provided with timely and understandable information to make responsible decisions about financial transactions," protecting consumers from "unfair, deceptive, or abusive acts and practices," and helping "markets for consumer financial products and services operate transparently and efficiently to facilitate access and innovation." ${ }^{141}$ Although automatic selling is ultimately practiced by merchants, its existence relies heavily upon retail financial products, such as debit and credit cards. By giving consumers greater control over their preauthorized payments, the CFPB is not only improving consumers' financial footing but also, in keeping with its mandate, increasing the safety and usefulness of those products.

\section{Advantages of the Authorization Catalogue}

Broadly speaking, the authorization catalogue has several distinct advantages over preexisting market structures and regulatory solutions. First, the proposal simplifies consumer choices, which in turn encourages smart consumer decisionmaking. Second, by designing a market in which abusive or exploitative practices cannot easily take root, the proposal protects more consumers than current methods, while reducing enforcement expenses.

\section{Simpler Consumer Choices}

People do not have unlimited cognitive resources. Today, few economists would dispute that individual consumers are governed by a form of "bounded rationality," in which mental heuristics, informational gaps, and unconscious biases constrain rational,

\footnotetext{
${ }^{138} 15$ USC § 1693b (c).

${ }^{139} 15$ USC § 1693d (a); 15 USC 1693e.

${ }^{140} 15$ USC § 1604 (a).

${ }^{141} 12$ USC § 5511 (b).
} 
utility-maximizing behavior. ${ }^{142}$ Choices with certain characteristics consistently frustrate rational decisionmaking.

Perhaps the most notable policy response to behavioral economic research has been "libertarian paternalism," developed and popularized by Cass Sunstein and Richard Thaler. ${ }^{143}$ The term has been applied to a diverse range of policies, but generally refers to attempts to guide consumers towards a "correct" choice without expressly mandating that choice, generally by relying on observed biases such as loss aversion. In doing so, it hopes to protect "irrational" consumers while preserving the ability of "rational" consumers to opt for a different course. For instance, after noting the tendency of financially lesssophisticated debit card holders to incur excessive overdraft fees, regulators required card issuers to disable overdraft protection by default. ${ }^{144}$

The overdraft fee regulation has not been a success. Banks did not find it difficult to encourage consumers to abandon the default option; they simply bombarded customers with information about the importance of avoiding overdrafts, and designed opt-in screens that funneled customers towards reenabling protection. ${ }^{145}$ One study estimates that up to $75 \%$ of customers retain overdraft protection - and among the "heavy users" who overdrafted frequently in the past, $98 \%$ are still subject to fees. ${ }^{146}$

This failure demonstrates a deeper flaw in some forms of libertarian paternalism. Behavioral economics does not suggest that consumers are helplessly in thrall to their cognitive biases, nor that they are neatly divided into "rational" and "irrational" categories. Instead, it paints a more nuanced picture of individual decisionmaking-one where individuals aspire to make utility-maximizing choices, but are hamstrung by limited mental capacity and limited information. Lacking omniscience, the consumer is forced to rely upon heuristics, shortcuts, assumptions, and other approximations of rationality. These approximations work better in some situations than others. Consumers who are forced to make more decisions, or harder decisions, also tend to engage in more disordered or irrational economic thinking-and sellers, knowing this, can encourage bad decisions by intentionally muddying the decision environment.

With that in mind, the authorization catalogue incorporates behavioral economic insights while eschewing certain tenets of libertarian paternalism. It does not attempt to protect so-called irrational consumers by disguising the choices they face, nor gently lead them towards policymakers' favored option. Instead, it relies on consumer agency, but in a

\footnotetext{
142 Daniel Kahneman, Maps of Bounded Rationality: Psychology for Behavioral Economics, 93 AMERICAN ECONOMIC REVIEW 1449 (2003).

${ }^{143}$ Richard Thaler and Cass Sunstein, Libertarian Paternalism, 93 AMERICAN ECONOMIC ReVIEW 175 (2003).

144 Lauren Willis, When Nudges Fail: Slippery Defaults, UNIVERSITY OF CHICAGO LAW REVIEW (forthcoming 2013).

145 Id. at 19-29.

146 Id. at $18-19$.
} 
greatly simplified decisionmaking context-a context in which even approximated rationality is likely to be sufficient. The catalogue-and-cancellation system clearly shows the relative costs and benefits of each option, and makes the process of choosing between them as quick and painless as possible.

Instead of relying on supposedly predictable irrationality, this proposal creates conditions ideal for rationality. The market does the rest of the work. In less than ten minutes, a consumer can easily evaluate all unnecessary or unwanted fee arrangements and prune them away, with little fear of penalty charges and no need to worry that a cancellation might be ignored.

\section{Market Self-Regulation}

Most regulation is essentially a two-step process: an activity is first legally proscribed, and then authorities set to work hunting down and preventing those activities. The authorization catalogue opts for a somewhat different approach: instead of telling merchants they're not allowed to use certain harmful sales tactics, it creates a market in which relying on those tactics is simply unviable. Of course, in doing so, it imposes restrictions on some private entities-banks and other financial intermediaries-but these entities are both fewer in number than potential violators, and have less financial selfinterest in flaunting payment rules.

This is desirable because, as the case studies demonstrate, abusive automatic selling is hard to detect and harder to eliminate. Sometimes, such as with self-renewing magazine subscriptions, it is difficult for third parties to distinguish between desired and unwanted automatic payments. Even in clear-cut instances of abuse, such as the Willms case, identifying a scheme's architect is a challenge for regulators. Unscrupulous sellers have a strong incentive to keep a low profile, they can hide behind shell companies, and their firms might be tiny or short-lived. Even once they have successfully identified a target for enforcement, regulators face considerable obstacles: building a case takes time, and not every merchant is an easy target for an enforcement action. (Recall that Willms himself resided in Canada; the FTC was forced to cooperate with Canadian authorities in prosecuting his case.)

But presumably at least one party does know when a particular transaction is unwanted: the customer himself. The authorization catalogue makes the consumer the primary regulator of automatic selling, by providing complete information about existing preauthorizations, and complete control over their cancellation. This solves several of the difficulties inherent in more active regulatory approaches. First, it eliminates the need to distinguish between positive and negative automatic sales; presumably, informed consumers will simply authorize the transactions they want. Second, it eliminates the need to identify non-compliant sellers. In order to cancel an authorization, a consumer does not 
need to correctly identify or successfully contact the responsible merchant; instead, all interactions are with the relevant financial intermediary. Likewise, the burden on government regulators is reduced: instead of monitoring every merchant, they only need to monitor financial intermediaries for compliance, most of which are already subject to relatively stringent regulation. Nor must compliance be complete-the authorization catalogue's implementation by most of the largest financial intermediaries would impact virtually all merchants. Finally, because the proposal would prevent the completion of offending transactions, the location, legal status, or identity of the merchant is essentially irrelevant. Assuming funds are being transferred through American intermediaries, a scammer operating in Azerbaijan would be subject to exactly the same transactional limitations as one operating in Chicago.

\section{The Private Ability to Contract: A Potential Loophole}

Implementing an authorization catalogue can go a long way towards helping consumers manage their finances and avoid unwanted preauthorized payment. It cannot, however, completely address the abuses of automatic selling.

The chief difficulty is the ability of merchants to rely upon private contract to enforce payment obligations. The authorization catalogue imposes a series of obligations on financial intermediaries while leaving consumers and producers to their own devices. As a result, it remains agnostic towards agreements between individual consumers and producers. Even if this paper's proposal is implemented in full, a consumer can still sign a contract agreeing to pay a cancellation fee or abide by certain restrictions when canceling an automatic payment. The proposal will give the customer the practical tools necessary to cancel payment; it will not, however, defeat his or her legal obligation to pay. The seller can, if so inclined, still seek to enforce payment by threatening or initiating legal action.

Although this apparent loophole certainly limits the scope of this paper's proposal, there are reasons to believe that the weakness may be less significant than it initially appears.

First, relying on contractual arrangements, by its very nature, draws attention to a customer's obligation to pay. While the only indication of an automatic payment may be an entry in a bank account's transaction log, a contractual obligation must be brought to a customer's attention in order to be enforced. Threatening legal action tends to defeat the consumer inertia that often makes automatic selling so profitable. This presumably increases the odds that a customer will fight the charge in some way, by seeking to cancel the service, refusing to pay, or some other means. (Even if individual consumers fail, collective awareness can also help breed collective anger, leading to large-scale responses such as the Scholastic class action.) 
Second, forcing sellers to rely on contractual arrangements places the onus on the sellers to pursue payments. They must threaten, cajole, or litigate consumers into submission. These options are time- and resource-intensive, endanger customer goodwill, and carry no guarantee of success. As the saying goes, possession is nine-tenths of the law: money that starts out in a customer's bank account is far more likely to end up there. Additionally, current automatic fee arrangements are usually not for very much money, on a per-customer basis, and most merchants, faced with the prospect of filing a lawsuit in order to recover $\$ 79.95$ in fees, would likely throw up their hands and eat the loss. In short, the same incentives that once worked against consumers would now work in their favor.

Third, merchants forced to seek legal redress are more likely to be subjected to preexisting statutory and regulatory consumer protections. As many of the case studies above demonstrate, abusive sellers frequently skirt state and federal rules governing automatic renewals and consumer notice-and at times, simply ignore those rules. This is partially possible because the odds of any given transaction being challenged in court are low. Those odds rise dramatically when sellers are unable to collect absent legal action.

Finally, it's worth noting that consumers already have the ability to stop payments through an account with a financial intermediary. Banks will stop individual credit card charges, even if they don't provide the option to cancel all preauthorized charges at once; likewise, debit card issuers are legally required to cancel payments upon request. In that situation, a merchant would need to approach a customer directly and seek redress. The authorization catalogue does nothing to limit or alter this process-it simply ensures that the payment system won't act as the merchant's institutional ally in a dispute.

\section{CONCLUSION}

Sometimes hard problems have simple solutions. Automatic selling looks like a very hard problem: it can be found in every corner of the economy, it can be almost impossible to distinguish useful arrangements from abusive schemes, and its harms are often subtle and corrosive, even to the individuals being injured. It's less of an acute illness, and more of a chronic condition-slowly draining consumer resources, but never quite meriting a full-fledged response from regulators. It's exactly the kind of economic malfeasance for which traditional regulation is poorly suited: the enforcers would be stuck forever playing whack-a-mole, knocking down small-scale violators only to find others cropping up in their place.

The answer, it turns out, is straightforward: by changing the context in which transactions occur, regulators can empower consumers to protect themselves. Armed with an authorization catalogue that clearly discloses the basic shape of preauthorized charges, and allows cancellation of unwanted charges, consumers can accomplish in a few minutes 
what had previously taken hours or days of effort. And why wouldn't they? The cost is minimal, the process is easy to understand, and the benefit might be huge.

As one final note, the principles underlying this solution may help solve other vexing problems as well. The simple idea behind the authorization catalogue-that consumers, with unambiguous information about a decision, and real, immediate agency over it, will choose in their self-interest-applies to many diverse situations. Consider the problem of overdraft fees. Although legally distinct from preauthorized payment, the basic problem is very much the same. Consumers are asked to preauthorize the purchase (through fees) of overdraft protection. But what would happen if they were asked to authorize the fees at the time of transaction instead? Many people, one suspects, would change their decision. And that's just the beginning. The modern economy is full of pitfalls for unwary decisionmakers. Maybe people making informed decisions will fare better.

When consumers are able to apply useful information to clearly defined choices, the market can be its best self: a place in which money is spent and goods are exchanged only because everyone involved wants it to happen. And isn't that the whole idea? 